\title{
Thinking Styles, Perceived Stress and Life Satisfaction
}

\author{
Jozef Bavolar \\ Pavol Jozef Šafárik University in Košice, Slovak Republic
}

\begin{abstract}
This study investigates the relationship between rational and experiential thinking styles, perceived stress and life satisfaction in university students. The research sample included 259 students $\left(56.8 \%\right.$ females, $\left.M_{\text {age }}=21.57\right)$ of psychology and informatics. Lower stress and higher life satisfaction are predominantly related to the thinking style preferred by the given gender the rational style in males and the experiential style in females. More positive results in stress and life satisfaction were observed in the groups scoring higher in both styles compared to those scoring lower in both thinking styles. The relationships between thinking style preferred by the given gender and life satisfaction are mediated by the perceived stress. The present results indicate the possibility of increasing life satisfaction through changing information processing modes.
\end{abstract}

Key words: thinking styles, rationality, intuition, stress, life satisfaction

\section{Introduction}

Dual-process theories of higher cognition (e.g., Betsch \& Kunz, 2008; Stanovich \&West, 2000) postulate the existence of two main types of information processing: the intuitive and analytical modes. These come under a number of different names but with very similar characteristics. Typically, intuitive (experiential ${ }^{1}$, Type 1 ) processes can be described as fast, parallel, nonconscious and automatic with a high capacityand ${ }^{1}$ We use the terms intuitive and experiential as syn-
onymous in this study

Acknowledgment: This work was supported by Scientific grant agency of the Ministry of Education, Science, Research and Sport of the Slovak Republic and of the Slovak Academy of Sciences - VEGA $1 / 0849 / 14$

Correspondence concerning this article should be addressed to Jozef Bavolar, Department of Psychology, Faculty of Arts, Pavol Jozef Šafárik University in Košice, Moyzesova 9, 04001 Košice, Slovak Republic, E-mail: jozef.bavolar@upjs.sk

Received December 12, 2016 importantrole of affective reactions, while rational(deliberative, reflective, Type 2) processes are slow, serial, conscious and controlled with limited capacity(Evans \& Stanovich, 2013). Newer approaches view thinking styles not as different processes, but as variations of Type 2 processes. The autonomous functioning and no requirement of working memory are considered to be the defining features of intuitive processes, while cognitive decoupling, mental simulation and requirement of working memory define reflective processes (Evans \& Stanovich, 2013).

The role of thinking styles in cognitive processes has been thoroughly described (e.g., Cano-Garcia \& Hughes, 2000), although their real life correlates remain unclear. The present study aims to fill this gap through the investigation of the relationship between the two major modes of information processing - the rational and intuitive modes - and two interrelated constructs - perceived stress and life satisfaction. Furthermore, given that gender differences have previously been reported in preferences to thinking style (Norris \& Epstein, 2011), this study is also aimed at examining the role of gender in this association. 
While individual differences in thinking styles and cognitive styles as a similar construct have been confirmed numerous times, their role in real-world decisions and their outcomes is questionable. Some authors have reported their inferior position in comparison with other variables. The effects of cognitive styles on real behavior are considered to be suppressed by other factors, such as general abilities and cognitive constraints (Kozhevnikov, 2007). In addition, it has been suggested that cognitive styles offer no incremental validity over decision-making styles in predicting decision-making outcomes (Dewberry, Juanchich, \& Narendran, 2013). On the other hand, the role of thinking styles has been found in some other areas. Sternberg \& Zhang (2001) have reported their predictive power for academic achievement and multiple studies have found them to be fundamental factors determining individual and organizational behavior (e.g., Sadler-Smith \& Badger, 1998; Streufert \& Nogami, 1989). Moreover, cognitive styles are a critical variable in personnel selection, internal communication, career guidance, counselling, and conflict management (Hayes \& Allinson, 1994). While the preference for intuitive processing has been found in some contexts (Agor, 1989; Simon, 1987), Baron (1998) has emphasized the role of analytical processes, or their combinations have been recommended (Hatsopoulos \& Hatsopoulos, 1999). The interplay of thinking styles with other characteristics was documented in a study by Pilárik and Sarmány-Schuller (2011), where rationality together with other variables formed clusters of adaptive characteristics (named as the resistant type - rationality, extraversion, conscientiousness and openness) or non-adaptive characteristics (failure to cope with emotions type - low rationality, neuroticism and emotional intelligence). Therefore, the evidence concerning the usefulness of thinking styles appears to be mixed. Generally, ra- tional thinking is a stronger predictor of adjustment (stress, depression, anxiety, general health, alcohol drinking) than intuitive thinking (Epstein et al., 1996).

Direct evidence about the relationship between thinking styles and life satisfaction has been limited. While both the rational and intuitive approaches to job searching result in greater job satisfaction and process satisfaction (Crossley \& Highhouse, 2005), the analytical or intuitive style were not found to be related to students' life satisfaction (Wraight, 2007). On the other hand, experiential, but not rational processing, was found to be positively related to the life satisfaction in Australian adults (Schutte et al., 2010). Similarly, as for life satisfaction, although the processes of thinking and decision-making under stress have been extensively studied (see Starcke \& Brand, 2012), the view on the relationship between perceived stress and cognitive styles can be adopted chiefly from the position of similar constructs, mainly decision-making styles. While Salo \& Alwood (2011) reported no significant relationships between the rational or intuitive decision-making style and stress in police officers, Bavolar \& Orosova (2015) found perceived stress to be negatively associated with the intuitive decision-making style and Lasikiewics (2015) reported its negative correlation with the rational thinking style. Correlations can depend on gender; stress was found to be more negatively associated with both the rational and experiential style in men than in women (Epstein et al., 1996). This finding is probably related to the gender differences in thinking styles. Males have been reported to use the rational style more and the experiential style less in comparison to females across different ages in numerous studies worldwide (e.g., Norris \& Epstein, 2011; Pacini \& Epstein, 1999; Sladek, Bond, \& Phillips, 2010) as well as in Slovakia (Ballová Mikušková, Hanák, \& Čavojová, 2015). 


\section{The Present Study}

The main goal of the present study was to investigate the relationships between the rational and experiential thinking on one hand and perceived stress and life satisfaction on the other hand. As previously noted, the evidence of the role of thinking styles in these two variables has been mixed and often comes from studies performed with affined constructs, such as decision-making styles or job satisfaction. The first aim of the current research was to provide a closer look at the bivariate relationships between each thinking style and perceived stress, or reason. The second aim was similar, but possible associations were examined from a different perspective. As most studies treat thinking styles separately without considering their interaction, this study tried to find a combination of thinking styles that could be considered to be adaptive in regard to stress and life satisfaction. The participants were grouped into four categories according to their combination of thinking styles, with high or low levels of both styles or with one prevailing style and compared in the discussed indicators. This classification of participants was inspired by some previous studies, where group membership was a result of a median split (Shiloh, Salton, \& Sharabi, 2002) or a cluster analysis (Wolfradt et al., 1999) and where this membership had an effect on the studied variables that was not identified by the bivariate associations.

The link between perceived stress and life satisfaction has been confirmed numerous times in very diverse samples, where higher perceived stress is related to lower life satisfaction in university student samples as well as in adults (e.g., Barnes \& Lightsley, 2005; Rey \& Extremera, 2015; Suh et al., 2016). Moreover, stress has not only been found to have an effect on well-being indicators including life satisfaction, but also to be an intervening variable in the rela- tionship between personality characteristics and life satisfaction (Hamarat et al., 2001; Rey \& Extremera, 2015). With these findings in mind, the third aim was to investigate the possible role of perceived stress as a mediator between thinking styles and life satisfaction. Given that thinking styles reflect the way of information processing, it is hypothesized that thinking styles affect how individuals perceive potentially stressful situations (direct effect of thinking styles on perceived stress) and this perception can be reflected in their life satisfaction (direct effect of perceived stress on life satisfaction). This expectation is mainly based on the previously proposed effect of thinking characteristics on the perception of stressful events (appraisal as the mediator between an event and its perception, e.g., Lazarus \& Folkman, 1984). Additionally, thinking styles have been found as predictors of perceived stress (e.g., Bavolar \& Orosova, 2015; Epstein et al., 1996), while the reversed path has, to the best of our knowledge, not been reported.

\section{Method}

\section{Sample}

The sample consisted of 259 university students (56.8\% females) from 18 to 29 years old $\left(M_{\text {age }}=21.57, S D=1.62\right)$, studying psychology $(N=131 ; 83.2 \%$ females $)$ or informatics $(N=$ $128 ; 29.7 \%$ females $)$. The students were asked to participate during their lessons. Informed consent was obtained from all participants included in the study.

\section{Measures}

The preference for the rational or experiential way of thinking was measured by The Rational-Experiential Inventory (REI-40 - Pacini \& Epstein, 1999; Ballová Mikušková et al., 2015), with 40 items divided into 20 items measuring 
Table 1 Gender distribution in thinking styles groups

\begin{tabular}{llcccc}
\hline & & $\begin{array}{l}\text { Complementary } \\
\text { thinking }\end{array}$ & $\begin{array}{c}\text { Rational } \\
\text { thinking }\end{array}$ & $\begin{array}{c}\text { Intuitive } \\
\text { thinking }\end{array}$ & $\begin{array}{l}\text { Poor } \\
\text { thinking }\end{array}$ \\
\hline males & $\mathrm{n}$ & 41 & 22 & 21 & 28 \\
\multirow{4}{*}{ females } & $\%$ & $37 \%$ & $20 \%$ & $19 \%$ & $25 \%$ \\
& $\mathrm{n}$ & 34 & 12 & 62 & 39 \\
& $\%$ & $23 \%$ & $8 \%$ & $42 \%$ & $26 \%$ \\
\hline
\end{tabular}

rational and 20 items measuring experiential cognitive style. Both styles can be divided into ability ( 10 items) and engagement - reliance on and enjoyment of the selected mode of thinking (10 items). Examples of items are "I enjoy intellectual challenges." (rational engagement), "I have a logical mind." (rational ability), "I like to rely on my intuitive impressions." (experiential engagement), and "I trust my initial feelings about people." (experiential ability).

Perceived stress was measured by the Perceived Stress Scale-4 (Cohen, Kamarck, \& Mermelstein, 1983), with four items answered on a scale from never (0) to very often (4). The higher the final score, the higher the level of perceived stress. The General Life Satisfaction Scale(Dalbert, 1992; Džuka \& Dalbert, 2002) was used to examine life satisfaction with a higher score meaning higher life satisfaction. The scale's seven items examine satisfaction of present as well as past life and future perspectives.

\section{Statistical Analysis}

Descriptive statistics and correlation analysis were carried out in the first step to investigate the relationships among thinking styles, their subscales, perceived stress and life satisfaction. In the next step, groups of subjects were created according to their combinations of thinking styles. K-means clustering divided subjects into four mutually exclusive groups. The "complementary thinking" group $(n=75)$ had high scores in both the rational and experiential style, and "poor thinking" group ( $n=$ 67) had low scores in both styles. The other two groups were characterized by the dominance of one thinking style - the rational style in the "rational thinking" group $(n=34)$ and the experiential style in the "intuitive thinking" group $(n=83)$. The groups differed in gender $\left(\chi^{2}(3)=21.313, p<.001\right)$ with a higher proportion of males in the "complementary thinking" and "rational thinking" groups and a higher proportion of females in the "intuitive thinking" group. About one quarter of males as well as females belonged to the "poor thinking" group (Table 1). A two-way ANOVA with gender and thinking styles group as factors was used to identify the role of thinking styles in perceived stress and life satisfaction. Mediation analysis was performed to verify the models with perceived stress as the mediator in the relationship between thinking styles and life satisfaction. Descriptive statistics, correlation analysis and groups comparison were performed in SPSS 21 and the mediation models were in SPSS AMOS 21.

\section{Results}

The descriptive statistics and correlations between all variables are provided in Table 2 . As males and females differed in both the rational style $\left(M_{\text {males }}=82.50, M_{\text {females }}=75.70, t=3.94\right.$, $p<.001, d=.50)$ and experiential style $\left(M_{\text {males }}=\right.$ $75.30, M_{\text {females }}=78.98, t=-2.16, p<.05, d=.27$ ), 
correlation analysis was performed separately for each gender. The rational thinking style was positively related to life satisfaction and negatively to the perceived stress in males. However, the relationships were substantially weaker in females. On the other hand, the experiential style was positively related to life satisfaction and negatively to stress in females, but not in males.

The possible interaction of thinking styles was investigated through the comparison of four groups created according to their scores in the rational and experiential style, with gender as the second factor included in a two-way ANOVA. The thinking styles groups differed in stress $\left(F(3,251)=4.71, p<0.01, \tau^{2}=0.05\right)$ and life satisfaction $\left(F(3,251)=3.32, p<0.05, \tau^{2}=\right.$ $0.04)$, but gender differences (stress: $F(1,251)=$ $0.81, p>0.05, \tau^{2}=0.00$; life satisfaction: $F(1,251)$ $\left.=1.79, p>0.05, \tau^{2}=0.01\right)$ as well as group $\mathrm{x}$ gender interactions (stress: $F(3,251)=1.05, p>$ $0.05, \tau^{2}=0.01$; life satisfaction: $F(3,251)=2.19$, $p>0.05, \tau^{2}=0.03$ ) were not significant. A post hoc comparison (Scheffé test) showed a significant difference $(p<0.05)$ in the same pair in both stress and life satisfaction; more positive scores (lower perceived stress and higher life satisfaction) were found in the "complementary thinking" group compared to the "poor thinking" group.

Table 2 Descriptive statistics, correlations and Cronbach's alphas for each variable

\begin{tabular}{lrrrrrrrrrrc}
\hline & $M$ & $S D$ & 1 & 2 & 3 & 4 & 5 & 6 & 7 & 8 \\
\hline Rational style (1) & 78.64 & 14.16 & .86 & $.88^{* * *}$ & $.87^{* * *}$ & $-.20^{*}$ & $-.28^{* *}$ & -.06 & $.36^{* *}$ & $-.32^{* *}$ \\
Rational engagement (2) & 37.41 & 7.56 & $.91^{* * *}$ & .75 & $.54^{* * *}$ & $-.22^{*}$ & $-.25^{* *}$ & -.15 & $.29^{* *}$ & $-.23^{*}$ \\
Rational ability (3) & 41.23 & 8.12 & $.92^{* * *}$ & $.67^{* * *}$ & .82 & -.12 & $-.24^{*}$ & .04 & $.34^{* * *}$ & $-.33^{* * *}$ \\
Experiential style (4) & 77.39 & 13.62 & .12 & .14 & .09 & .87 & $.91^{* *}$ & $.89^{* *}$ & .06 & -.11 \\
Experiential engagement (5) & 38.12 & 7.81 & .02 & .05 & -.02 & $.92^{* * *}$ & .80 & $.61^{* * *}$ & .09 & -.01 \\
Experiential ability (6) & 39.27 & 7.17 & $.22^{* *}$ & $.21^{* *}$ & $.19^{*}$ & $.92^{* * *}$ & $.69^{* * *}$ & .78 & .01 & $-.20^{*}$ \\
Life satisfaction (7) & 30.53 & 6.74 & .14 & .11 & .13 & $.22^{* *}$ & $.20^{*}$ & $.22^{* *}$ & .89 & $-.54^{* *}$ \\
Stress (8) & 7.07 & 2.80 & $-.19^{*}$ & -.16 & $-.19^{*}$ & $-.21^{*}$ & -.12 & $-.27^{* *}$ & $-.50^{* * *}$ & .73 \\
\hline
\end{tabular}

Note. Cronbach's alphas are on diagonal. Correlations for females are under the diagonal, for males above the diagonal.

${ }^{*} p<0.05,{ }^{* *} p<0.01,{ }^{* * *} p<0.001$

Table 3 Mean values of perceived stress and life satisfaction in thinking styles groups

\begin{tabular}{llrc}
\hline Variable & Group & $M$ & $S D$ \\
\hline \multirow{3}{*}{ life satisfaction } & complementary & 31.81 & 6.78 \\
& rational & 30.97 & 5.74 \\
& intuitive & 30.69 & 5.98 \\
& poor & 28.66 & 7.72 \\
\hline \multirow{4}{*}{ stress } & complementary & 6.20 & 2.83 \\
& rational & 6.82 & 3.04 \\
& intuitive & 7.28 & 2.78 \\
& poor & 7.91 & 2.40 \\
\hline
\end{tabular}


As the thinking styles were related to stress and life satisfaction, the next step of analysis was a verification of the mediation model with perceived stress as the hypothesized mediator between thinking style and life satisfaction. Since the thinking styles were only weakly associated with each other and gender differences in them were found, four possible mediation models (separately for each style and gender) were considered. The direct effect of the ratio- nal style on life satisfaction in females $(\beta=.14$, $p>0.05$ ) as well as the direct effect of the experiential style on life satisfaction in males $(\beta=$ $.02, p>0.05$ ) were low and not significant, thus, the possible mediating effect of stress was only examined in the relationship between the rational style and life satisfaction in males and between the experiential style and life satisfaction in females. Standardized regression coefficients are provided in Figure 1.

a)

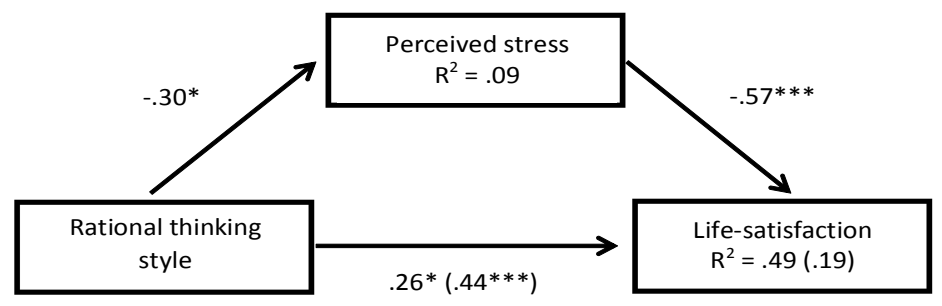

b)

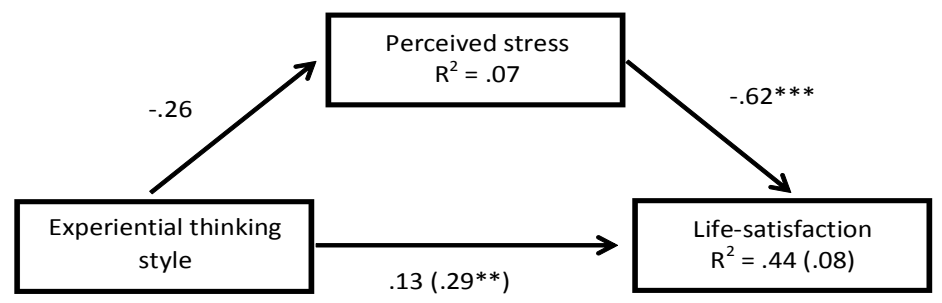

Note. The standardized regression coefficients and indexes of determination for direct effects are in parentheses.

Figure 1 Standardized regression coefficients for the relationships between the thinking styles (a) rational thinking style in males, b) experiential thinking style in females) and life satisfaction as mediated by perceived stress. 
A partial mediation was found in the relationship between the rational thinking style and life satisfaction in males and a full mediation in the relationship between the experiential thinking style and life satisfaction in females. The standardized indirect effect in the first model was .17 and .16 in the second model. The significance of this indirect effect was tested using bootstrapping procedures with 10,000 bootstrapped samples, when the $95 \%$ confidence interval was computed by determining the indirect effects at the 2.5th and 97.5th percentiles. The $95 \%$ confidence interval ranged from .03 to .39. in the first model and from .02 to .32 . in the second model. Thus, both the indirect effects were statistically significant.

\section{Discussion}

The relationships between the rational and experiential thinking styles on one hand and stress and life satisfaction on the other hand were the center of interest in the current study, but no thinking style was found to be more advantageous, as perceived stress and life satisfaction are associated with the style dominant for a given gender; the more positive values of perceived stress and life satisfaction are related to the rational thinking style in males, but to the experiential thinking style in females. Previous research has brought very heterogeneous results concerning the given relationships, which can partially be explained by different research designs. Previous studies have differed in samples (students, adults, the addicted, paramedics), measures (REI, Preference for Intuition/ Deliberation, General Decision-Making Style) and variables (always only stress or only life satisfaction was present) and have mostly adopted a bivariate approach. The aim of the present research was to determine if there is a style or a combination of two prominent thinking styles that can be considered to be adaptive-connected with the more positive results in both studied variables. The results indicate that this expectation has only partially been shown - the relationships and differences are very similar across the two included variables but are determined by gender to a high degree.

While gender differences in thinking styles have been widely reported (Ballová Mikušková et al., 2015; Pacini \& Epstein, 1999; Sladek et al., 2010), gender-dependent relationships have not been the primary object of interest in thinking styles research. Studies examining the associations of thinking styles with other variables almost always report only overall correlations and are not interested in possible gender-dependent patterns. In contrast, it is not rare that research reports related to stress and life satisfaction divide samples in order to observe the relationships separately in males and females (e.g., Fiori et al., 2006; Fugl-Meyer, Melin, \& Fugl-Meyer, 2002; Tait, Padgett, \& Baldwin, 1989). The rare exception in thinking styles research can be found in the pioneering article by Epstein et al. (1996), who reported substantially different correlations of the REI scales in males and females with various other variables. It seems surprising that even this study, cited in numerous thinking styles research reports, has not riveted attention to the gender aspect. The present results signalize that gender preference of thinking styles has to be taken into account. This is the case even when the other variables do not differ as in the present study, where the gender differences in perceived stress and life satisfaction were not significant.

In addition, a group comparison has indicated that it is impossible to declare one thinking style as more advantageous than the other. The "rational thinking" group does not differ from the "intuitive thinking" group and although the only significant difference was a better result of the "complementary thinking" group when compared with the "poor thinking" group, a tendency of a group can signalize a certain pattern. In both perceived stress and life satisfac- 
tion, the "rational thinking" and "intuitive thinking" group are in the middle, with more positive values than the "poor thinking" group but with more negative values than the "complementary thinking" group. Both styles seem to be equally useful and their combination is even more advantageous than using just one of them. Different approaches emphasize rational thinking (expected utility theory) or intuitive thinking (a fast-and-frugal heuristics approach, Todd \& Gigerenzer, 2012) and the current study does not solve this controversy. The current gender-dependent results may serve as a possible explanation for the ambiguous results of previous studies - the relationships present in males and females have been mixed in these studies and the final results may have been influenced by the gender ratio.

The relationship between thinking styles and life satisfaction was mediated by stress, but mediation was only found in the thinking styles dominant for the given gender. The current findings indicate that the way of thinking can affect how we perceive demanding situations and their requirements and this perception is reflected in satisfaction with life. A change of information processing style can possibly influence life satisfaction through perceived stress. As Epstein et al. (1996) theorize, thinking styles are responsible for receptivity to different kinds of communication. They report thinking styles to be related to social and emotional adjustment and the present findings also support a cognitive approach to personality and well-being. These results can be useful for practitioners whose interventions should take into account the thinking style preferred by the individual whilst also considering the general gender-dependent tendency.

The generalization of the results is mainly limited by the characteristics of the sample and by the measures used. The sample includes only university students from two study fields whose experiences and effect on stress and life satis- faction can be uniform. Moreover, as gender was found to be a crucial variable in the current study, it should be emphasized that gender was highly associated with the field of study; most females studied psychology and most males informatics. Since the study field could affect the preferred thinking style, the style may have been a factor influencing the selection of the study field. The possibility that the found gender differences could be the result of differences in the study field cannot be disproved. More heterogeneous samples with a wider age and education range are needed to verify the present results. In addition, only self-reported measures were used. While it is common in most studies, a more direct way of identifying thinking styles (e.g., assessment of preferred information processing style by people familiar to subjects (see Norris \& Epstein, 2011) or observation during various tasks) can bring more valid findings. The found relationships may not only reflect the effect of the information processing style on perceived stress and life satisfaction, but also a stable pattern of viewing an individual's own psychological characteristics. Furthermore, while a mediation effect of perceived stress was observed, a cross-sectional design of the study does not allow direct causal inferences to be made. Longitudinal studies are needed to verify a possible mediation.

To conclude, this study provides a view of the role of thinking styles in perceived stress and life satisfaction. Based on the results, the dominance of one thinking style as more adaptive with regard to possible decision consequences was not identified, as the findings depend on gender. Gender has to be taken into account in future thinking styles research and although thinking styles are only weakly related to each other, their mutual combinations seem to be a promising trend of future research. The adoption of longitudinal research would be useful in investigating possible causal relationships. 


\section{References}

Agor, W. H. (1989). Intuition in organizations: Leading and managing productively. Newbury Park, CA: Sage Publications.

Ballová Mikušková, E., Hanák, R., \& Čavojová, V. (2015). Appropriateness of two inventories measuring intuition (The PID and the REI) for Slovak population. Studia Psychologica, 57(1), 63-82.

Barnes, P. W., \& Lightsey, O. R. (2005). Perceived racist discrimination, coping, stress, and life satisfaction. Journal of Multicultural Counseling and Development, 33(1), 48-61.

Baron, J. (1998). Judgment misguided: Intuition and error in public decision making. New York: Oxford University Press.

Bavolar, J., \& Orosova, O. (2015). Decision-making styles and their associations with decision-making competencies and mental health. Judgment and Decision Making, 10(1), 115-122.

Betsch, C., \& Kunz, J. J. (2008). Individual strategy preferences and decisional fit. Journal of Behavioral Decision Making, 21(5), 532-555.

Cano-Garcia, F., \& Hughes, E. H. (2000). Learning and thinking styles: An analysis of their interrelationship and influence on academic achievement. Educational Psychology, 20(4), 413-430.

Cohen, S., Kamarck, T., \& Mermelstein, R. (1983). A global measure of perceived stress. Journal of Health and Social Behavior, 24(4), 385-396.

Crossley, C. D., \& Highhouse, S. (2005). Relation of job search and choice process with subsequent satisfaction. Journal of Economic Psychology, 26(2), 255-268.

Dalbert, C. (1992). Subjektives Wohlbefinden junger Erwachsener: Theoretische und empirische Analysen der Struktur und Stabilität. Zeitschrift für Differentielle und Diagnostische Psychologie, 13(4), 207-220.

Dewberry, C., Juanchich, M., \& Narendran, S. (2013). Decision-making competence in everyday life: The roles of general cognitive styles, decision-making styles and personality. Personality and Individual Differences, 55(7), 783-788.

Džuka, J., \& Dalbert, C. (2002). Vývoj a overenie validity škál emocionálnej habituálnej subjektívnej pohody (SEHP). Československá Psychologie, 46(3), 234-250. [Elaboration and verification of emotional habitual subjective well-being scales (SEHP)]

Epstein, S., Pacini, R., Denes-Raj, V., \& Heier, H. (1996). Individual differences in intuitive-experiential and analytical-rational thinking styles. Journal of Personality and Social Psychology, 71(2), 390405 .
Evans, J. S. B., \& Stanovich, K. E. (2013). Dual-process theories of higher cognition: Advancing the debate. Perspectives on Psychological Science, 8(3), 223-241.

Fiori, K. L., Brown, E. E., Cortina, K. S., \& Antonucci, T. C. (2006). Locus of control as a mediator of the relationship between religiosity and life satisfaction: Age, race, and gender differences. Mental Health, Religion and Culture, 9(3), 239-263.

Fugl-Meyer, A. R., Melin, R., \& Fugl-Meyer, K. S. (2002). Life satisfaction in 18- to 64-year-old Swedes: In relation to gender, age, partner and immigrant status. Journal of Rehabilitation Medicine, 34(5), 239-246.

Hamarat, E., Thompson, D., Zabrucky, K. M., Steele, D., Matheny, K. B., Aysan, F. (2001). Perceived stress and coping resource availability as predictors of life satisfaction in young, middle-aged, and older adults. Experimental Aging Research, 27(2), 181-196.

Hatsopoulos, N. G., \& Hatsopoulos, G. N. (1999). The role of tacit knowledge in management. In $\mathrm{R}$. $\mathrm{J}$. Sternberg \& J. A. Horvath (Eds.), Tacit knowledge in professional practise: Researcher and practitioner perspectives (pp. 141-152). Mahwah, NJ: Erlbaum.

Hayes, J., \& Allinson, C. W. (1994). Cognitive style and its relevance for management practice. British Journal of Management, 5(1), 53-71.

Kozhevnikov, M. (2007). Cognitive styles in the context of modern psychology: Toward an integrated framework of cognitive style. Psychological Bulletin, 133(3), 464-481.

Lasikiewicz, N. (2015). Perceived stress, thinking style, and paranormal belief. Imagination, Cognition and Personality, 35(3), 306-320.

Norris, P., \& Epstein, S. (2011). An experiential thinking style: Its facets and relations with objective and subjective criterion measures. Journal of Personality, 79(5), 1043-1080.

Pacini, R., \& Epstein, S. (1999). The relation of rational and experiential information processing styles to personality, basic beliefs, and the ratio-bias phenomenon. Journal of Personality and Social Psychology, 76(6), 972-987.

Pilárik, L, \& Sarmány-Schuller, I. (2011). Personality predictors of decision-making of medical rescuers. Studia Psychologica, 53(2), 175-184.

Rey, L., \& Extremera, N. (2015). Core self-evaluations, perceived stress and life satisfaction in Spanish young and middle-aged adults: An examination of mediation and moderation effects. Social Indicators Research, 120(2), 515-524.

Sadler-Smith, E., \& Badger, B. (1998). Cognitive style, learning and innovation. Technology Analysis \& Strategic Management, 10(2), 247-266. 
Salo, I., \& Alwood, M. (2011). Decision-making styles, stress and gender among investigators. Policing, 34(1), 97-119.

Shiloh, S., Salton, E., \& Sharabi, D. (2002). Individual differences in rational and intuitive thinking styles as predictors of heuristic responses and framing effects. Personality and Individual Differences, 32(3), 415-429.

Schutte, N. S., Thorsteinsson, E. B., Hine, D. W., Foster, R., Cauchi, A., \& Binns, C. (2010). Experiential and rational processing styles, emotional intelligence and wellbeing. Australian Journal of Psychology, 62(1), 14-19.

Simon, H. A. (1987). Making management decisions: The role of intuition and emotion. The Academy of Management Executive (1987-1989), 57-64.

Sladek, R. M., Bond, M. J., \& Phillips, P. A. (2010). Age and gender differences in preferences for rational and experiential thinking. Personality and Individual Differences, 49(8), 907-911.

Stanovich, K. E., \& West, R. F. (2000). Individual differences in reasoning: Implications for the rationality debate? The Behavioral and Brain Sciences, 23(5), 645-726.

Starcke, K., \& Brand, M. (2012). Decision making under stress: A selective review. Neuroscience \& Biobehavioral Reviews, 36(4), 1228-1248.

Sternberg, R. J., \& Zhang, L. F. (2001). Thinking styles across cultures: Their relationships with student learning. In R. J. Sternberg \& L. F. Zhang (Eds.),
Perspectives on thinking, learning and cognitive styles (pp. 227-247). Mahwah, NJ: Erlbaum.

Streufert, S., \& Nogami, G. Y. (1989). Cognitive style and complexity: Implications for I/O psychology. In C. L. Cooper \& I. Robertson (Eds.), International review of industrial and organizational psychology (pp. 99-143), Chichester: Wiley.

Suh, H., Rice, K. G., Choi, C. C., van Nuenen, M., Zhang, Y., Morero, Y., \& Anderson, D. (2016) Measuring acculturative stress with the SAFE: Evidence for longitudinal measurement invariance and associations with life satisfaction. Personality and Individual Differences, 89, 217-222.

Tait, M., Padgett, M. Y., \& Baldwin, T. T. (1989). Job and life satisfaction: A reevaluation of the strength of the relationship and gender effects as a function of the date of the study. Journal of Applied Psychology, 74(3), 502-507.

Todd, P. M., \& Gigerenzer, G. (2012). Ecological rationality: Intelligence in the world. New York: Oxford University Press.

Wolfradt, U., Oubaid, V., Straube, E. R., Bischoff, N., \& Mischo, J. (1999). Thinking styles, schizotypal traits and anomalous experiences. Personality and Individual Differences, 27(5), 821-830.

Wraight, M. E. (2007). The impact of trait emotional intelligence and cognitive style on the academic achievement and life satisfaction of college students (Doctoral dissertation). Retreived from ProQuest Dissertations and Theses. (UMI No 3277707). 